\title{
RBEP
}

\section{Políticas inovadoras para o ensino médio no Brasil: um estudo de caso do ProEMI}

\author{
Eliza Bartolozzi Ferreira ${ }^{\mathrm{I}, \mathrm{II}}$ \\ Leonara Margotto Tartaglia ${ }^{\text {III,IV }}$ \\ Roberta Freire Bastos ${ }^{\mathrm{V}, \mathrm{VI}}$
}

\section{Resumo}

Este artigo objetiva analisar o Programa Ensino Médio Inovador (ProEMI) no estado do Espírito Santo, no período entre 2012 e 2016. Nosso argumento é que a implantação das políticas educacionais pelos sistemas de ensino é traduzida de variadas formas de acordo com a realidade educacional e cultural de cada instituição. Do ponto de vista epistemológico, trabalhamos com a perspectiva da análise cognitiva de políticas públicas. Utilizamos uma metodologia qualitativa, desenvolvida em cinco escolas da rede estadual, com entrevistas, grupos focais e aplicação de um survey. Os dados coletados revelaram que a implantação do ProEMI ocorreu conforme a realidade do sistema educacional e de cada escola. Os principais resultados do Programa, segundo os participantes da pesquisa, foram: o recebimento dos recursos financeiros; sua gestão proporcionando experiências aos docentes e aos seus estudantes até então não vivenciadas por esses sujeitos; e novas relações de trabalho e de perspectivas de ensino-aprendizagem. Isso não é tudo o que o Programa se propôs a realizar, mas é algo novo, simbólico e representativo do investimento estatal no ensino médio, movimento que, na atualidade, caminha do lado oposto.

Palavras-chave: análise cognitiva de políticas públicas; ensino médio; políticas educacionais; Programa Ensino Médio Inovador.

\footnotetext{
Universidade Federal do Espírito Santo (Ufes). Vitória, Espírito Santo, Brasil. E-mail: <eliza.bartolozzi@ gmail.com $>$; <https://orcid. org/0000-0002-4100-9875>.

II Doutora em Educação pela Universidade Federal de Minas Gerais (UFMG). Belo Horizonte, Minas Gerais, Brasil.

III Centro Educacional Agostiniano. Vitória, Espírito Santo, Brasil. E-mail: <leonaramargotto@ gmail.com>; <https://orcid. org/0000-0002-0455-4903>.

IV Mestra em Educação pela Universidade Federal do Espírito Santo (Ufes). Vitória, Espírito Santo, Brasil.

v Universidade Federal do Espírito Santo (Ufes). Vitória, Espírito Santo, Brasil. E-mail: <bastosrobertafreire @gmail.com>; <https:// orcid.org/0000-0003-4497$8206>$

vI Mestra em Educação pela Universidade Federal do Espírito Santo (Ufes). Vitória, Espírito Santo, Brasil.
} 


\section{Abstract \\ Innovative policies for secondary education in Brazil: a case study of ProEMI}

This article aims to analyze the Innovative High School Program (ProEMI) in the state of Espírito Santo, on the period between 20122016. Our argument is that the implementation of educational policies by education systems are translated in various ways according to the educational and cultural reality of each institution. From the epistemological point of view, we work with the perspective of the cognitive analysis of public policies. We used a qualitative methodology, developed in five schools of the state network, with interviews, focus groups and a survey. The data collected revealed that the implementation of ProEMI occurred according to the reality of the educational system and of each school. The main results of the Program, according to the research subjects, were: the receivement of the financial resources; its management providing experiences to the teachers and their students not previously experienced by these subjects; new work relations and teaching-learning perspectives. This is not all that the Program has set out to do, but it is something new, symbolic and representative of state investment in the high school stage, a movement that nowadays is on the opposite side.

Keywords: cognitive analysis of public policies, educational policies, high school; Innovative High School Program.

\section{Resumen \\ Políticas innovadoras para la educación secundaria en Brasil: un estudio de caso del ProEMI}

Este artículo tiene como objetivo analizar el Programa Educación Secundaria Innovadora (ProEMI) en el estado del Espírito Santo, en el período entre 2012 y 2016. Nuestro argumento es que la implantación de las políticas educativas por los sistemas de enseñanza se traduce de variadas formas, de acuerdo con la realidad educativa y cultural de cada institución. Desde el punto de vista epistemológico, trabajamos con la perspectiva del análisis cognitivo de políticas públicas. Utilizamos una metodología cualitativa, desarrollada en cinco escuelas de la red estatal, con entrevistas, grupos focales y la aplicación de un survey. Los datos recogidos revelaron que la implantación del ProEMI ocurrió de acuerdo con la realidad del sistema educativo y de cada escuela. Los principales resultados del Programa, según los sujetos de la investigación, fueron: la recepción de recursos financieros; su gestión, que proporcionó experiencias a los profesores y sus alumnos hasta entonces no experimentadas por estos sujetos; y nuevas relaciones de trabajo y perspectivas de enseñanzaaprendizaje. Esto no es todo lo que el Programa se propuso realizar, pero es 
algo nuevo, simbólico y representativo de la inversión estatal en la educación secundaria, movimiento que, en la actualidad, camina del lado opuesto.

Palabras clave: análisis cognitivo de políticas públicas; educación secundaria; políticas educativas; Programa Educación Secundaria Innovadora.

\section{Introdução}

Este artigo tem o objetivo de contribuir com os estudos sobre avaliação dos impactos de políticas educacionais implantadas no Brasil. Especificamente, busca analisar os efeitos da implementação de uma política para o ensino médio brasileiro e aborda implantação do Programa Ensino Médio Inovador (ProEMI) no Espírito Santo, no período 2012-2016. Entendemos que avaliar a implantação de uma política pública não é uma tarefa simples, pois não basta analisar como foi realizada a aplicação da política na prática a partir dos seus documentos orientadores. Sendo assim, uma avaliação não trata de verificar se o resultado da implantação de um programa educativo transcorreu de maneira positiva ou negativa tão somente referenciado naquilo que foi formulado.

Acreditamos que a avaliação dos efeitos de uma política passa pela análise do seu processo, compreendida aqui como uma análise sobre as formas de tradução da política na prática educativa e sobre seus efeitos para a transformação de uma determinada realidade escolar. Desse modo, este artigo propõe analisar os efeitos da implantação do ProEMI em cinco escolas da rede estadual no Espírito Santo, o que implica compreender um processo perpassado por conhecimentos construídos com base nos valores, nas representações e nas crenças que fundam o exercício docente.

O ProEMI foi criado em 2009 pelo Ministério da Educação (MEC) e estabelecido pelo Parecer CNE/CP n 11/2009 com a finalidade de apoiar e fortalecer os sistemas estaduais de educação na adoção de propostas curriculares inovadoras nas escolas de ensino médio não profissionalizantes. De acordo com o documento orientador (Brasil. MEC, 2011), esse Programa integra as ações do Plano de Desenvolvimento da Educação (PDE), como estratégia do governo federal para induzir a reestruturação dos currículos do ensino médio. Parte-se da ideia de que as ações propostas devam ser incorporadas ao currículo das escolas, ampliando o tempo nas instituições e a diversidade de práticas pedagógicas, de modo a atender às necessidades e expectativas dos estudantes do ensino médio.

A partir de nossa pesquisa, argumentamos que a implantação das políticas educacionais pelos sistemas de ensino é traduzida de variadas formas de acordo com a realidade educacional e cultural de cada instituição. Essa constatação nos leva a acreditar que é grande a probabilidade de que as políticas educacionais não sejam executadas na sua integralidade ou, até mesmo, possam assumir outras características diferentes do planejado. 
O termo "tradução" significa transformação e faz referência à integração de determinado problema na agenda política, cujo exercício pode ocorrer em diferentes níveis da matriz cognitiva e normativa anteriormente formulada (Muller; Surel, 2002).

O estudo sobre a implantação do ProEMI é aqui desenvolvido com base na perspectiva teórico-metodológica de Pierre Muller (2015), que entende as políticas públicas como processos, nos quais são elaboradas as representações de uma sociedade. Este texto é um recorte de uma pesquisa realizada no período 2012-2016 com financiamento do Conselho Nacional de Desenvolvimento Científico e Tecnológico (CNPq). A investigação nasceu com o objetivo de analisar as potencialidades, os desafios e as fragilidades no processo de implantação do ProEMI no estado do Espírito Santo.

Este artigo está organizado em três sessões, além desta introdução e das considerações finais. A primeira sessão aborda os aspectos teóricometodológicos que orientaram a pesquisa; a segunda apresenta uma breve exposição sobre os referenciais global e setorial que perpassam a discussão sobre o ensino médio; e a terceira faz uma descrição analítica sobre o ProEMI, bem como analisa os dados coletados.

\section{Aspectos teórico-metodológicos da pesquisa}

Do ponto de vista epistemológico, esta pesquisa aborda a perspectiva da análise cognitiva de políticas públicas, cuja base está na sociologia da ação pública de Pierre Muller (2015). Para o autor, uma política pública se apresenta sob a forma de programa de ação governamental em um setor da sociedade ou em um espaço geográfico, ou seja, um lugar onde as sociedades definem sua relação com o mundo e com elas mesmas. Muller (2015) considera que a política pública é um construto social e de pesquisa.

Nesse prisma, a representação do real e a consequente imagem cognitiva que os atores organizam sobre a percepção de um problema configuram o referencial de uma política, coexistindo um referencial global, formado por um conjunto de valores fundamentais que constituem as crenças de base de uma sociedade, e um referencial setorial, que é uma representação do setor, da disciplina ou da profissão. Os valores e os argumentos que os compõem são questões de conflito e são continuamente balizados no campo intelectual por seus mediadores (Ferreira, 2018).

O processo de construção de uma matriz cognitiva é um movimento de poder pelo qual um ator faz valer e afirma seus próprios interesses. Uma relação circular existe com efeito entre lógicas de sentido e lógicas de poder, por meio das quais o ator constrói o sentido que toma a liderança do setor que afirma sua hegemonia, tornando-se legítimo o referencial ou o paradigma em consequência dessa estabilização das relações de força. "A produção de uma matriz cognitiva não é, portanto, um simples processo discursivo, mas uma dinâmica intimamente ligada às interações e às relações de força que se cristalizam pouco a pouco num setor" (Muller, 2015, p. 49). 
Muller e Surel (2002) entendem que o estudo de políticas públicas exige considerar o conjunto dos indivíduos, grupos ou organizações cuja posição é afetada pela ação do Estado em um determinado espaço. Isso ocorre porque uma política pública possibilita aos atores compreender as transformações de seu contexto, oferecendo-lhes um conjunto de relações e de interpretações causais que lhes permite decodificar, decifrar os acontecimentos com os quais eles são confrontados.

Para Muller (2015), podemos identificar três maneiras de construir um questionamento a propósito das políticas públicas, as quais não são completamente independentes. A primeira abordagem coloca acento sobre a gênese das políticas públicas e procura responder às questões: por meio de quais processos sociais, políticos ou administrativos estão presas as decisões que constituem as políticas? Como nascem e se transformam as políticas públicas? A pesquisa, segundo o autor, consistirá em "contar a história" de uma mudança mediante a evidência de variáveis que permitem explicá-la.

A segunda abordagem focaliza o estudo da caixa preta do Estado: como funciona o sistema de ação concreta por meio do qual é elaborada e implantada uma política pública? A questão é saber como se posicionam os atores administrativos e privados envolvidos na elaboração e implantação da obra de uma política. O terceiro questionamento coloca o problema nos efeitos das políticas sobre a sociedade: como medir ou avaliar o impacto de uma política no campo social e econômico? A questão é saber se a política estudada modificou o tecido social que esperava afetar e em que medida seus efeitos estão em conformidade com as expectativas daqueles que a decidiram.

O objetivo deste texto é responder ao terceiro questionamento como maneira de avaliar os efeitos da implantação do ProEMI em cinco escolas da rede estadual do Espírito Santo. Entendemos que há um espaço entre a política e a prática, no qual diversos atores entram em cena e produzem experiências diversas entre o enunciado pela política e sua realidade.

\subsection{Procedimentos metodológicos}

A seleção das cinco escolas se deu a partir dos critérios de tempo de implantação (início em 2012) e da localização das escolas (em diferentes regiões do estado). Após a definição dos critérios, foi realizado um sorteio, de modo que foram selecionadas escolas localizadas na Região Metropolitana da Grande Vitória e nas regiões norte e sul do estado. Das cinco escolas sorteadas, três estão situadas na Grande Vitória, uma no norte e outra no sul do estado, e em todas elas a implantação do ProEMI teve início em 2012. Adotamos a metodologia qualitativa como meio de explorar as contradições e os antagonismos vividos pelos atores sociais. Ao mesmo tempo, usamos dados estatísticos e financeiros como mecanismos para obter a análise dos recursos financeiros executados pelo Fundo Nacional de Desenvolvimento da Educação (FNDE) na implantação do ProEMI. 
As cinco unidades escolares estão localizadas em regiões distintas entre si, sendo os contextos e as realidades diferentes importantes aspectos para permitir a investigação das estratégias e as possibilidades de implementação do ProEMI. A produção de dados da pesquisa amostral desenvolveu-se no período de 2013 a 2016, por meio de diversas técnicas: entrevistas semiestruturadas e grupos focais com gestores e professores que participaram do ProEMI nas cinco unidades de ensino, um survey e uma extensa análise documental.

Neste artigo, serão discutidas as seguintes categorias: a avaliação (do Programa/financiamento/inovação); o perfil e as condições do trabalho docente; a implantação do ProEMI e os efeitos desta nas cinco escolas da amostra.

\section{O Programa Ensino Médio Inovador - seu surgimento e sua organização}

O ProEMI emerge em meio à inserção do ensino médio na agenda das políticas públicas do MEC a partir de um contexto democrático de participação dos estados da Federação vivenciado no período do Governo Lula (2003-2010). Nesse período, de acordo com Ferreira (2018), não obstante a globalização e seu referencial do mercado dominarem a agenda política e econômica brasileira, como pode ser observado pelas ações governamentais de atendimento da ordem global, a questão social fez também parte dessa agenda. Assim, tanto a educação básica (e suas modalidades) como a superior foram tratadas como direito social e foram criadas políticas para ampliar o acesso mesmo em um cenário de restrições orçamentárias diante das necessidades históricas da educação brasileira.

O referencial setorial que fez emergir o ProEMI, em 2009, começou pouco a pouco, em 2003, quando os debates e disputas tiveram campo fértil para se expressarem. O cerne dos debates foi a disposição do MEC em superar o dualismo estrutural entre a educação básica e profissional (Ferreira, 2018, p. 9).

Mesmo vivendo profundas contradições no referencial global e no setorial (educação), o MEC criou o ProEMI: uma proposição da Diretoria de Concepções e Orientações Curriculares e da Coordenação Geral do Ensino Médio, a partir de um modelo fundamentado no debate em curso das Diretrizes Curriculares Nacionais do Ensino Médio (2012) e, também, das reivindicações dos estados, principalmente por meio do Fórum Nacional dos Coordenadores do Ensino Médio.

O ProEMI foi instituído pela Portaria Ministerial n 971, de 9 de outubro de 2009 (Brasil. MEC, 2009), e implementado, como um projeto-piloto, no ano de 2009. Seu início ocorreu em 2010 com a adesão de sete escolas de alguns estados da Federação. Conforme o artigo $2^{\circ}$ da Portaria Ministerial, "o Programa visa apoiar as Secretarias Estaduais de Educação e do Distrito Federal no desenvolvimento de ações de melhoria da qualidade do ensino 
médio não profissionalizante [...]" (Brasil. MEC, 2009). Segundo dados retirados do portal do MEC (Brasil. MEC, 2015), em nível nacional, até o ano de 2015, o Programa contava com a adesão de 10.701 escolas. No Espírito Santo, foi implantado em 2012 e, em 2014, contava com a adesão de 197 escolas de um total de 293 escolas estaduais.

A base do Programa consistia na discussão curricular que seria estabelecida pelas próprias escolas de ensino médio, conforme a necessidade e a realidade local. Além da inovação curricular, os objetivos do ProEMI englobavam, entre outros, um protagonismo dos sujeitos do processo educativo (adolescentes e jovens) e a articulação entre as redes pública e privada de ensino, com institutos federais e instituições do Sistema S.

De acordo com o documento orientador (Brasil. MEC, 2009, art. $2^{\circ}$ ), a ênfase curricular deveria estar em:

projetos pedagógicos que promovam a educação científica e humanística, a valorização da leitura, da cultura, o aprimoramento da relação teoria e prática, da utilização de novas tecnologias e o desenvolvimento de metodologias criativas e emancipadoras.

Nessa direção, do ponto de vista curricular, a proposta explicitada nos documentos orientadores (Brasil. MEC, 2009; 2011; 2013) indica que, à luz de um processo dinâmico, participativo e contínuo, devem ser estimuladas novas formas de organização das disciplinas integradoras, as quais devem se apoiar nas inter-relações existentes entre os eixos constituintes do ensino médio: o trabalho, a ciência, a tecnologia e a cultura.

A política que se estimava para o ensino médio visava superar os problemas históricos da dualidade (ensino profissionalizante e ensino propedêutico), da reprovação e do abandono, a partir do protagonismo das próprias escolas por meio do desenvolvimento das ações definidas nos macrocampos dos Planos de Redesenho Curricular (PRCs), com financiamento garantido pelo poder público. A escola seria responsável por definir, pelo PRC, onde os recursos do Programa deveriam ser investidos com a finalidade de alterar a configuração atual para superar as suas dificuldades e intervir diretamente na política educacional em curso.

A partir do seu lançamento, o ProEMI passou por várias reformulações, que vão desde os seus pressupostos teóricos até as orientações didáticometodológicas, mas guardou seu caráter de uma política educacional que visava induzir mudanças, por dentro, na organização pedagógica das escolas, principalmente nos modos de conceber e tratar os sujeitos, os tempos, os espaços e o conhecimento escolar.

Tanto as Diretrizes Curriculares Nacionais (Resolução CNE/CEB $n^{\circ}$ 2/2012) quanto as orientações do ProEMI tratam com a mesma importância a constituição dos currículos dentro de cada instituição de ensino, incentivando sua construção de forma contextualizada e interdisciplinar, utilizando diferentes maneiras de interação e articulação entre os distintos campos do conhecimento. Trata-se de uma política de indução do protagonismo dos trabalhadores docentes e dos alunos na construção do currículo. 
A perspectiva de organização curricular apresentada no documento orientador do ProEMI pressupunha a possibilidade de articulação interdisciplinar voltada para o desenvolvimento de conhecimentos diversos e propunha um processo dinâmico, participativo e contínuo que fosse capaz de estimular novas formas de organização das disciplinas articuladas com atividades integradoras. Essa dinâmica deveria ser traçada a partir das inter-relações existentes entre o eixo constituinte do ensino médio firmado pelas Diretrizes Curriculares Nacionais (2012) para essa etapa, ou seja, o trabalho, a ciência, a tecnologia e a cultura (Brasil. MEC, 2009).

Segundo Jakimiu (2014), as contribuições mais significativas do ProEMI referem-se à sua tentativa de induzir um novo currículo, que vai ao encontro das expectativas dos jovens, à ampliação do tempo desse jovem na escola, assim como aos recursos destinados a ela. A autora destaca a importância das atividades que visam promover uma educação tanto científica quanto humanista, a valorização da leitura, o aperfeiçoamento da relação teoria e prática, o estímulo ao uso de novas tecnologias e o desenvolvimento de metodologias criativas e emancipadoras (Jakimiu, 2014).

Assim como Jakimiu (2014), Isleb (2014) aponta contribuições relevantes do ProEMI para o desenvolvimento do ensino médio e, especialmente, destaca a importância do Parecer CNE/CEB no 5/2011, que trata das novas Diretrizes Curriculares Nacionais para o Ensino Médio (DCNEM). Ao fazer uma comparação das DCNEM (Resolução n 2/2012) com as Diretrizes Curriculares Nacionais de 1998, a autora observa que o documento de 2012 anuncia mudanças significativas para a organização curricular do ensino médio, visto que se apoia na perspectiva de uma formação unitária, integrada e articulada aos eixos trabalho, cultura, ciência e tecnologia. Especificamente sobre o ProEMI e sua relação com essas novas diretrizes, a autora considera que:

\begin{abstract}
O Programa Ensino Médio Inovador-ProEMI apresenta consonância com as novas Diretrizes Curriculares Nacionais para o Ensino Médio. Ambos pretendem dialogar com os desafios presentes nesta etapa. Além disso, propõem uma formação humana que busca consolidar a identidade do ensino médio como parte da educação básica; adequar o currículo aos sujeitos; cumprir com os artigos 35 e 36 da Lei de Diretrizes e Bases da Educação Nacional-LDBEN, n. 9.394/96, que tratam das finalidades e da organização curricular da última etapa da educação básica (Isleb, 2014, p. 20).
\end{abstract}

\section{Análise dos dados da pesquisa}

A implementação do ProEMI no Espírito Santo (2012) ocorreu de modo sistemático por meio da coordenação da Secretaria de Educação (Sedu) e de suas Superintendências Regionais de Educação (SREs). Com base nos relatos coletados nos grupos focais realizados nas cinco escolas, bem como nas entrevistas com técnicos da Sedu, as orientações para sua implantação aconteceram em reuniões intituladas "formativas" com a presença de diretores, pedagogos e professores que buscavam entender como desenvolver o trabalho operacionalmente. 
O instrumento do questionário foi enviado para as escolas por meio da ferramenta Google docs, mas tivemos um número pequeno de retorno. Nossa segunda estratégia foi deixar os questionários impressos com a direção de cada escola, e recebemos um número um pouco maior de respostas. Por fim, enviamos um grupo de pesquisadores aos locais para finalizar a coleta dos dados. No total, foram 100 questionários respondidos dentro do universo de 176 professores. Após a sistematização dos dados levantados no survey, fizemos dois grupos focais em cada escola com o objetivo de suprir as lacunas encontradas pelo questionário. Cada grupo focal contou, em média, com oito participantes. Apresentamos, a seguir, alguns dados analisados mediante o cruzamento do conjunto desses procedimentos metodológicos.

\subsection{Perfil dos sujeitos da pesquisa}

Os respondentes dos questionários são, majoritariamente, mulheres (68,6\%), brancas (62,6\%), com idade entre 37 e 58 anos (53,5\%), que dividem seu tempo em outras atividades além da profissão, como leitura de revistas e jornais $(57,5 \%)$, atividade física $(54,5 \%)$, serviços domésticos $(51,5 \%)$ e atendimento à família $(48,4 \%)$.

Esses dados constatados em nível local e nacional confirmam que a educação básica conta com uma grande quantidade de profissionais brancas do sexo feminino. Diante desse recorte, podemos inferir que são profissionais que possuem dupla jornada, pois 50\% afirmam ter compromisso com os serviços domésticos e o atendimento à família. Porém, mesmo diante da dupla jornada, conseguem se organizar e ainda destinam parte de seu tempo às leituras extras e às atividades físicas.

Quando se trata do perfil formativo, a maioria possui curso superior em licenciatura (98\%), com graduação em instituição particular (56,6\%) e especialização $(76,7 \%)$. Atrelado ao perfil formativo, esses profissionais trabalham na educação entre 11 e 20 anos (46\%); atuam no ensino médio de um a dez anos (49,4\%); sem outro vínculo empregatício na educação (61,6\%); e com remuneração que varia de três a cinco salários mínimos (46\%).

Chama a atenção a quantidade de professores jovens nas salas de aula, e, quando usamos o termo jovens, referimo-nos àqueles com até dez anos de profissão, sendo cerca de $50 \%$. É importante destacar que a carga horária de trabalho e a condição salarial se apresentam precárias tendo em vista o grau elevado da formação acadêmica da maioria quando comparado ao de outras profissões no Brasil.

\subsection{Condições do trabalho docente e a implantação do ProEMI}

Analisando as condições do trabalho docente, os números mostram que são professores (84,4\%); com turmas que variam de 36 a 45 alunos (69,7\%); atuantes na escola da pesquisa entre um e dez anos $(59,9 \%)$; 
de vínculo efetivo $(67,7 \%)$; com carga horária entre 16 e 25 horas na escola pesquisada $(48,4 \%)$; e com uma a dez horas de trabalhos escolares realizados em casa $(58,5 \%)$.

Quanto à carga horária de trabalho, 55,5\% dos profissionais da educação disseram que, com a implantação do ProEMI, não houve alteração da carga horária, 26,2\% afirmaram que houve e 13,1\% não souberam responder. Esses dados revelam que as escolas pouco conseguiram transformar sua organização do trabalho e que apenas um grupo de profissionais atuou diretamente no ProEMI. Nos grupos focais, ficou evidenciado que as mudanças previstas pelo Programa dependiam do esforço da Sedu de garantir mais profissionais para as escolas e isso não foi cumprido. O sistema estadual apenas assegurou o aumento da carga horária para um número pequeno de professores, ficando este diretamente responsável pela coordenação das atividades curriculares. Mesmo assim, os respondentes relataram a realização de vários projetos que movimentavam a vida estudantil e provocavam uma ressignificação do currículo compreendida como a promoção de condições reais para o exercício de práticas inovadoras que envolveram os estudantes em atividades extraescolares, proporcionando ações pedagógicas que valorizavam o protagonismo dos alunos.

Com a sistematização dos dados coletados no survey, identificamos que aos docentes foi delegada a função de implementação do ProEMI. Para 46,4\% dos docentes, a adesão ao Programa efetivou-se em 2012. Em contrapartida, 31,1\% dos professores não souberam responder. Para entender como foi realizada essa adesão, os respondentes do survey, que poderiam escolher até três respostas, informaram os motivos para adesão ao Programa: orientação da Sedu (44,4\%); decisão do diretor $(40,4 \%)$; e desejo dos professores (33,3\%). A menor adesão dos docentes pode ser compreendida pela desconfiança que adquiriram em relação aos programas dos governos diante das constantes mudanças tão comuns no movimento "zig-zag" característico da gestão das redes públicas de ensino (Cunha, 2009).

Afirmaram conhecer os documentos orientadores do Programa 47\% dos docentes. Logo, praticamente a metade dos respondentes não dominam as diretrizes do Programa e podem se sentir incapacitados para avaliar seus efeitos. Os dados mostram que mais da metade dos respondentes não conseguiram avaliar a execução dos PRCs. Essas informações foram destacadas nos grupos focais, e houve o entendimento de que o ProEMI não envolveu toda a escola, isto é, muitos professores continuaram com sua prática docente e apenas um grupo participou efetivamente do Programa. Mas essa realidade esteve mais presente nas escolas localizadas na metrópole, pois, nas duas escolas do interior do estado, o envolvimento foi bem maior, conforme veremos adiante.

Além do fato de o Programa envolver um quantitativo limitado de profissionais em cada escola, há outro elemento relevante da realidade educacional que vale lembrar - a intensa rotatividade dos profissionais. Atuam como professores temporários 32,3\% dos respondentes. Importa ressaltar que, mesmo com os efetivos, é possível que haja uma rotatividade 
dos docentes entre as instituições, principalmente aquelas de bairros periféricos nos quais os índices de criminalidade são maiores. Duas escolas da nossa amostra se enquadram nesse quesito.

As variáveis, rotatividade e não participação de toda a escola no Programa, são fenômenos que possuem uma forte tendência a influenciar políticas educacionais, pois remetem às dificuldades da organização escolar, que, no geral, é dependente da gestão financeira e pedagógica dos sistemas educacionais. Essa realidade pode favorecer diversas formas de tradução do ProEMI, com grande probabilidade de não serem seguidos os princípios e objetivos previstos na sua formulação. Na melhor hipótese, as escolas criam novas experiências se as possibilidades estiverem abertas, e esse seria o caso do ProEMI. Segundo o Conselho Nacional de Educação (CNE), o Programa é uma política que expressa o "acertado entendimento" de que ninguém mais do que a própria comunidade escolar conhece a sua realidade e, portanto, está mais habilitada para tomar decisões a respeito do currículo (Parecer CNE/CP no 11/2009). Logo, com os recursos financeiros recebidos pelas escolas com a implantação do ProEMI somados às orientações gerais enviadas pelo MEC, a escola (re)criou várias dinâmicas de trabalho. Os dados apresentados a seguir dão uma dimensão da questão.

Em consonância com o exposto sobre a participação no Programa, a informação de que as condições de trabalho melhoraram para $49,4 \%$ dos entrevistados é um importante sinal para nossa pesquisa. Para 11,1\% não houve mudança, e 32,3\% não souberam responder. Em relação à gestão escolar, 54,5\% dos docentes disseram que houve melhoria, $6 \%$ disseram que não e 30,3\% não souberam responder. Essa porcentagem é mais ou menos equivalente ao número de professores com contratos temporários.

\subsection{Efeitos da implantação do ProEMI}

Quando se trata do planejamento integrado entre os professores e as áreas de conhecimento propostas pelo Programa, 41,4\% dos docentes afirmaram que houve essa integração, 7\% disseram que não houve e 30\% não souberam responder. Com a possibilidade de fazer até três escolhas na questão referente à implantação do PRC, os respondentes destacaram que este promoveu práticas inovadoras (56,5\%); estimulou a participação e a autonomia dos alunos nas atividades escolares (28,2\%); promoveu a melhoria no desempenho dos alunos (23,2\%); e conseguiu inovar o currículo escolar $(22,2 \%)^{1}$.

Os docentes asseveraram que, com o ProEMI na escola, houve aumento da diversidade das práticas pedagógicas $(41,4 \%)$; a interdisciplinaridade passou a ser mais reforçada pelo conjunto dos professores (37,3\%); os professores passaram a planejar suas aulas a partir dos eixos trabalho, ciência, cultura e tecnologia (25,2\%); entre outros (20,0\%). É interessante notar que $20 \%$ dos trabalhadores docentes não responderam a essa questão; 45,4\% afirmaram que, nas ações desenvolvidas nos PRCs, há uma mudança constante das práticas pedagógicas; $7 \%$ disseram que não; e outros $40 \%$ não souberam responder. Essas altas porcentagens de sujeitos que não
Essa questão poderia ter até três escolhas. 
responderam, ou não sabem, confirmam a interferência das variáveis: a rotatividade dos professores e a não participação de toda a escola no Programa.

Em relação à estrutura física da escola, pequenas reformas foram realizadas no quadro do ProEMI e equipamentos foram comprados. Os mais recorrentes foram: laboratório de ciências, física e química $(45,4 \%)$; aquisição de datashow (45,4\%); livros literários (41,4\%); equipamento audiovisual (39\%). No entanto, 34\% dos respondentes afirmaram não saber se houve investimentos dessa natureza. Por sua vez, $44,4 \%$ dos professores informaram que houve melhoria da estrutura física da escola com o ProEMI, $12,1 \%$ disseram que não e 37,3\% não souberam responder. Mais uma vez, uma taxa próxima ao número de professores com contrato temporário.

No tocante à formação continuada, 50,5\% disseram que houve espaço para a revisão do currículo e $45,4 \%$ que não. Segundo $54,4 \%$ dos respondentes, essa formação contribuiu para a prática pedagógica, 31,1\% disseram que não e 14,1\% não responderam.

Especificamente sobre a inovação curricular - objeto do ProEMI -, os respondentes entendem que a inovação passa, basicamente, pelos seguintes critérios (poderiam ser sinalizados até três): a) promover o protagonismo estudantil (54,5\%); b) desenvolver aulas dinâmicas interdisciplinares (50,5\%); c) fortalecer a igualdade de oportunidades no acesso aos saberes escolares (38,3\%); d) promover um currículo escolar mais includente (27,2\%); e e) garantir a formação da cidadania e para o trabalho (26,2\%). Esses dados podem ser cruzados com as práticas anunciadas pelos professores quando questionados sobre o trabalho pedagógico: $47,4 \%$ apontaram que suas práticas estão dispostas para orientar os alunos para valores e práticas da cidadania; 17,1\% para preparar os alunos para o Exame Nacional do Ensino Médio (Enem) e/ou vestibular; e 16,1\% para atender às Diretrizes Curriculares Nacionais para o Ensino Médio (2012).

Nesse cruzamento, observamos que os professores entendem que promovem o protagonismo dos alunos ao orientá-los para valores e práticas da cidadania. Sentem também que, preparando-os para o Enem (ou vestibular), eles contribuem para fortalecer a igualdade de oportunidades no acesso aos saberes escolares. Assim, nos PRCs de todas as escolas, foram contemplados cursos preparatórios para o Enem sem, necessariamente, haver o registro formal dessa atividade. Esse dado revela a realidade das escolas brasileiras que se encontram divididas entre promover práticas diversificadas e inovadoras e atender à política de avaliação, buscando cumprir com todas as tarefas, não obstante as suas contradições.

\subsection{Especificidades na implantação do ProEMI nos grupos de escolas}

As primeiras escolas estaduais que aderiram ao ProEMI o fizeram por ser um Programa que provocava mudanças na forma "tradicional" de trabalho na sala de aula, substituindo-a por oficinas e/ou aulas de campo. O objetivo dos gestores escolares era tornar a escola mais atrativa e 
mais significativa para o aluno. Com isso, buscaram desenvolver práticas consideradas inovadoras porque rompiam com o espaço da sala de aula.

De modo geral, no primeiro momento, os professores das cinco escolas receberam o Programa como mais uma atividade obrigatória e, posteriormente, compreenderam que era uma boa proposta porque recebiam recursos financeiros que possibilitariam a execução de atividades pedagógicas diferenciadas até então difíceis de implantar por falta de verba. Ao mesmo tempo, os professores entrevistados das escolas do interior do estado conseguiram desenvolver os projetos previstos no ProEMI no corpo do currículo, durante o trabalho pedagógico da sala de aula, pois, segundo eles, os alunos usavam o transporte escolar e não poderiam ficar mais tempo na escola. Mesmo assim, do ponto de vista dos entrevistados, essas práticas seguiram uma proposta inovadora desejada por muitos, mas que sofria o limite financeiro, superado pela verba do ProEMI.

\subsubsection{Escolas da Grande Vitória}

Na primeira escola, situada em Vitória, nem todos os alunos e nem todos os professores (cerca de 40\%) participaram. As oficinas eram desenvolvidas em um horário diferenciado da sala de aula, portanto, não havia necessariamente uma integração com o currículo escolar, levando a crer que dois "mundos" diferentes existiam na escola. Os professores que trabalharam no ProEMI recebiam a hora extra. Segundo os participantes dos grupos focais, os alunos que frequentavam as oficinas tiveram uma experiência positiva e se engajaram mais no contexto da escola, o que comprovava a importância de a escola adotar práticas pedagógicas diversificadas e inovadoras.

Nas entrevistas e nos grupos focais realizados na segunda escola, localizada em um município da região da Grande Vitória e tradicionalmente reconhecida pelo bom trabalho prestado, o Programa possibilitou uma formação continuada dos professores. Nos relatos, fomos informados de que algumas ações, no âmbito do Programa, foram realizadas por trabalhadores que atuavam de forma voluntária, devido ao fato de os recursos não chegarem conforme o planejado. Ressaltaram que as atividades executadas fortaleceram o vínculo entre professor e estudante e que observavam a exigência, por parte da direção e dos alunos, de uma prática pedagógica comprometida com o Programa, que incluía oficinas de teatro, literatura e esportes.

Com relação ao financiamento, a diretora da primeira escola pontuou que o ProEMI possibilitou a contratação de professores para a realização de ações planejadas no âmbito do programa, a melhoria na estrutura da unidade de ensino e a compra de equipamentos para laboratórios. A segunda diretora ressaltou o caráter instável da política de financiamento, que algumas ações aconteceram mesmo sem o recurso financeiro, por meio do trabalho voluntário, e ainda destacou a falta de financiamento da alimentação e do transporte para os alunos. 
No que tange ao currículo, na explanação da primeira diretora, fica evidente a relação com o Programa Mais Educação, pois ocorreu a ampliação da carga horária do aluno para sete horas, com a realização de oficinas. Para ela, os estudantes aceitaram bem a proposta, visto que as atividades proporcionaram a ressignificação e a reflexão em torno do currículo. Segundo a diretora, os documentos orientadores foram utilizados na elaboração do PRC e foram realizadas adaptações curriculares, as quais promoveram atividades de iniciação científica e pesquisa, cultura e artes, cultura corporal etc.

Em outra escola, localizada em um terceiro município na Grande Vitória, a situação encontrada foi bem diferente. A entrevista com a diretora, que não participou de todo o processo do ProEMI, apontou que o Programa foi importante para a escola. Ela admitiu que, ao chegar à escola, deparou-se com um assoberbamento de atividades para desenvolver, o que a levou a optar pelo que era mais emergencial. Segundo a diretora, o fato de ter muitas tarefas para administrar criou um receio de errar, e isso causou a paralisação de algumas atividades. Além de relatar sobre a intensificação de seu trabalho, destacou que há uma alta rotatividade dos professores contratados via designação temporária (DT), os quais são maioria na escola. Com a virada do ano letivo, novos professores contratados chegam às escolas para realizar o que foi planejado por outros. Às vezes, esses novos contratados nem chegam a ter conhecimento do que foi planejado anteriormente. Nessa terceira escola, especificamente, observamos que o ProEMI não modificou o cotidiano nem chegou a influenciar as práticas pedagógicas. Provavelmente, a maior presença de DTs na escola traz particularidades ao trabalho, o que fica evidente pela fala da diretora:

[...] Nove efetivos somente, aqui é uma escola com muito DT. Não é normal assim isso tudo né, mas é uma escola de muito, muito, muito DT. Quando eu entrei no estado eu era daqui, efetiva, uma época que saíram, por exemplo, onze de uma vez só, em uma remoção. Então é uma escola que tem bastante DT (Diretora 3, 2016).

Relativamente ao financiamento do ProEMI nas escolas, a proposta do documento era prestar apoio técnico e financeiro após uma análise dos projetos elaborados pelas secretarias de educação. Com a aprovação das propostas dos estados (os PRCs), os convênios seriam estabelecidos para a transferência de recursos federais aos estados em forma de execução direta ou descentralizada. Desse modo, o ProEMI foi inserido no PDE e seus recursos eram recebidos pelas unidades escolares por meio do Programa Dinheiro Direto na Escola (PDDE).

Os documentos orientadores (Brasil. MEC, 2009, 2011, 2013, 2014) definiram os critérios de financiamento para o Programa de acordo com cada escola. Em 2009, o documento baseava-se na matrícula para a definição do valor a ser encaminhado (custeio e capital). A partir do ano de 2011, foram determinadas duas tabelas para o estabelecimento do valor a ser repassado às unidades escolares: 1) matrícula, jornada de cinco a sete horas ou escola que atende o ensino médio noturno; e 2) matrícula e jornada de tempo integral - sete horas ou mais na escola. A seguir, apresentamos os recursos 
financeiros recebidos pelas cinco escolas nos primeiros anos da implantação do ProEMI. Segundo os sujeitos da pesquisa, esses recursos fizeram muita diferença no trabalho escolar, pois a escola nunca havia recebido tanto dinheiro e com liberdade de execução em projetos pedagógicos escolhidos por ela própria.

Tabela 1 - Recursos financeiros destinados às escolas pesquisadas por ano e recebimento (valores em $\mathrm{R} \$$ )

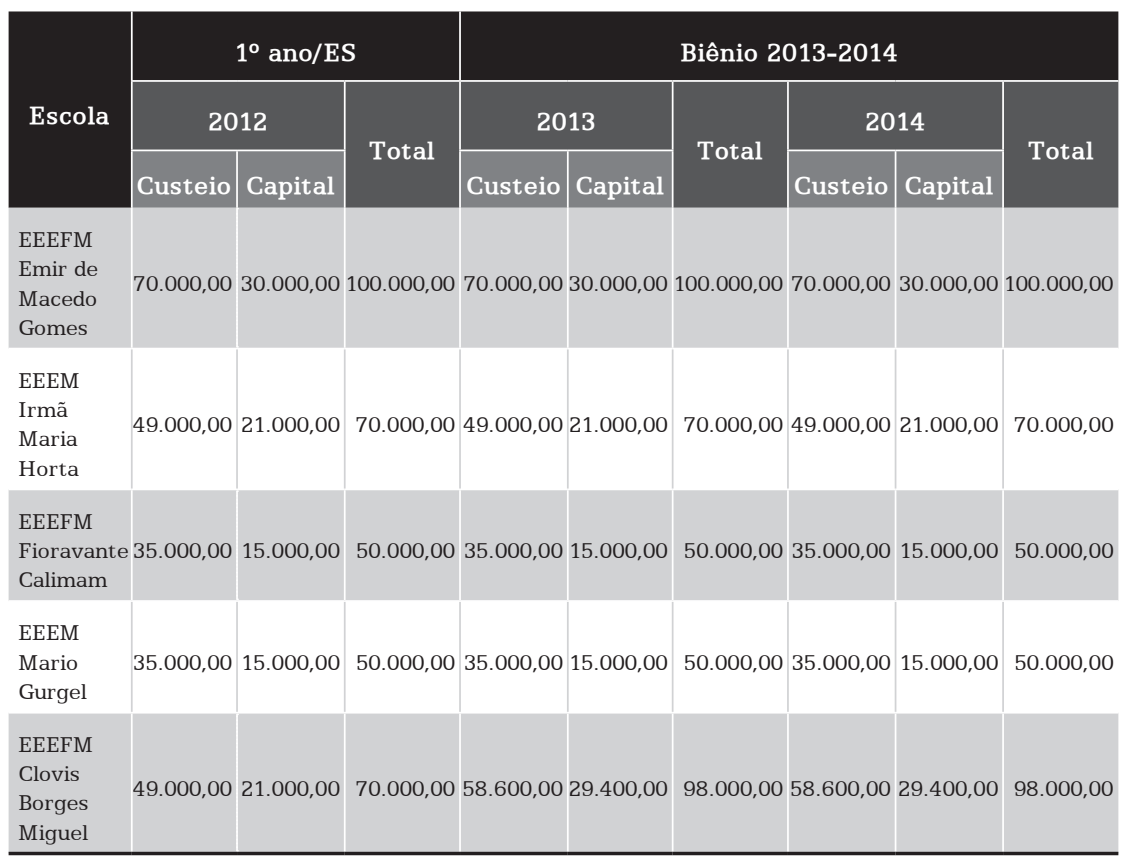

EEEFM - Escola Estadual de Ensino Fundamental e Médio.

EEEM - Escola Estadual de Ensino Médio.

Fonte: Elaboração própria baseada em Planos de Redesenho Curricular das escolas e Espírito Santo. Sedu, SEE (2016).

Nas cinco escolas pesquisadas, os recursos financeiros recebidos no âmbito do ProEMI promoveram significativos avanços pedagógicos e de infraestrutura. Na segunda escola, os recursos possibilitaram a contratação de professores para a realização de ações planejadas no âmbito do Programa (proporcionando diversificar as atividades pedagógicas), a melhoria na estrutura da unidade de ensino e a compra de equipamentos para laboratórios. A gestora ressaltou que os recursos, às vezes, demoravam um pouco mais para chegar à escola. Mesmo assim, a instituição se sentia motivada a realizar algumas ações sem o recurso financeiro, mediante o trabalho voluntário.

Há um reconhecimento, por parte da direção da terceira escola, de que "o ProEMI é um recurso muito pedagógico" (Diretora 3, 2014). Não obstante ser o ProEMI entendido como mais um recurso na escola, essa fala demonstra que ele tem um caráter diferenciado dos demais, pois atende mais ao objetivo pedagógico das ações escolares. Para a diretora, o recurso é percebido como um potencializador das atividades pedagógicas 
já desenvolvidas pela escola. Muitas atividades que antes ficavam apenas no planejamento, com o ProEMI, foram realizadas. Realidade semelhante foi apresentada na primeira escola pesquisada.

Os recursos do ProEMI foram utilizados pela terceira escola, principalmente, para equipar a unidade de ensino. Nessa escola, por exemplo, a direção, quando perguntada sobre a necessidade de equipar os laboratórios, respondeu positivamente: "[...] tem, essa é uma das ações pelo que eu vi" (Diretora 3, 2016). E continua, em seguida, mostrando a planilha de recursos do ProEMI: "Aqui oh, aula de campo, aula de campo, visita, oficinas, equipar laboratório de física e matemática com equipamentos, tal tal e tal" (Diretora 3, 2016). Essas ações foram consideradas pela diretora um dispositivo de desenvolvimento de ações inovadoras que provocaram a diversificação das práticas pedagógicas até então existentes na escola, de modo que os alunos tiveram novas oportunidades de aprendizagem e de exercício de seu protagonismo.

\subsubsection{Escolas localizadas no interior do estado}

Na quarta escola, situada no interior do estado, todos os alunos e professores participaram do ProEMI. Na quinta, localizada em cidade de grande porte, a dinâmica do ProEMI foi semelhante à das escolas da Grande Vitória. Todos os profissionais participantes da pesquisa concordaram que o ProEMI se tornou um excelente recurso para que as atividades planejadas pela escola, algumas em prática mesmo antes da criação do Programa, pudessem ser ampliadas e fortalecidas. Nessas escolas, o Programa foi mais valorizado pelo seu caráter de financiamento do que de estimulador de mudanças curriculares. Durante os grupos focais, os gestores e os professores articuladores do Programa destacaram as aulas de campo como um elemento de importante enriquecimento da aprendizagem dos alunos.

As análises sobre os recursos do ProEMI na quarta escola apontam para mudanças na infraestrutura da unidade e para os projetos realizados. Quando a coordenadora foi questionada sobre a avaliação do ProEMI, do ponto de vista pedagógico, ela respondeu que, no início, o Programa foi assustador e que chegou como mais uma demanda: "mais uma função, mais um trabalho" (Coordenadora 4, 2016). Em compensação, "ele dava o recurso que o professor solicitava e, com esse recurso, era possível envolver muita coisa" (Coordenadora 4, 2016). A coordenadora afirmou, categoricamente, que os recursos financeiros eram a grande vantagem do ProEMI. Quando o repasse foi interrompido, houve estranhamento e paralisação de algumas relevantes atividades pedagógicas que demandavam investimentos financeiros.

Ademais, os relatos descreviam o ProEMI como um programa que permitia "agregar as outras disciplinas de uma forma interdisciplinar. Então, envolvia bastante a escola" (Coordenadora 4, 2016). Portanto, mesmo quando a questão se refere ao aspecto pedagógico, o financiamento decorrente da execução do Programa é citado como o grande avanço, em 
que pese o fato de não haver uma narrativa sobre a proposta curricular. Por sua vez, os entrevistados reconheciam que as atividades pedagógicas puderam ser ampliadas com mais liberdade.

O conceito de inovação, presente na diretriz do Programa, é relacionado à execução de projetos e à liberdade de desenvolvimento do currículo:

E aí, é esse olhar diferenciado que você pode ter a liberdade de estender uma forma diferente de abordar o currículo, o conteúdo [...] Você não fica preso, né, àquela rotina diária de conteúdo e quadro e coisa e tal... [...] Você busca uma coisa diferente que você queria apresentar. Dá, dá uma certa liberdade (Coordenadora 4, 2016).

A pesquisa de Bormann (2017) indica que as inovações pedagógicas nas escolas públicas previstas pelo ProEMI envolvem no currículo a incorporação da diversidade de atividades planejadas nos PRCs e, também, a ampliação do tempo na escola, na perspectiva da educação integral. Sendo assim, a inovação pressupõe um redesenho curricular e, no nosso estudo de caso, ela se revelou como uma ação fragmentada e esporádica.

Na quinta escola, os recursos do ProEMI foram utilizados para equipar os laboratórios de química, matemática, biologia e a biblioteca, além da aquisição de materiais pedagógicos e aulas de campo. Tais investimentos proporcionaram aos professores a possibilidade de desenvolver projetos mais ousados e significativos para os alunos. "A escola se tornou mais interessante [...] tinha mais motivação sim" (Diretor 5, 2016).

Além dos investimentos materiais, os recursos foram utilizados para manter um profissional responsável pela biblioteca, o que oportunizou um acesso mais amplo dos alunos: "[...] às vezes, você passava nos corredores, na fila da merenda, eles estavam lendo, você descia uma escada quando eles estavam de aula vaga, eles estavam lendo [...] hoje a gente tem uns alunos que realmente são leitores [...]" (Professora 5, 2016).

A possibilidade das novas estruturas na escola - laboratórios equipados, materiais diversificados -, bem como condições de realizar aulas de campo, proporcionou melhores condições de trabalho e, por conseguinte, mais motivação e comprometimento com as aulas. Os professores passaram a ter condições de fazer um planejamento objetivamente possível, "[...] tudo até que era um sonho, virou uma realidade e culminou assim como uma ação concreta [...]" (Coordenadora 5, 2016). O fato de ter novas instalações "[...] causa um impacto no trabalho do professor" (Diretor 5, 2016).

De acordo com relatos coletados nas entrevistas e nos grupos focais, o ProEMI fortaleceu os momentos de planejamento interdisciplinar em decorrência dos PRCs. Os professores reuniam-se semanalmente para planejar, momento em que as discussões-tratavam desde a proposta curricular até a culminância das atividades, que muitas vezes era uma aula de campo.

Nossa pesquisa evidenciou que o currículo escolar adotado pela rede estadual era praticado ao mesmo tempo que funcionavam as oficinas ou as aulas de campo previstas nos PRCs. Considerando que os recursos 
financeiros do ProEMI, de acordo com os entrevistados, serviram para executar projetos já existentes na escola e que estavam engavetados ou sendo executados parcialmente, podemos afirmar que o Programa não trouxe de fato uma mudança curricular. Todavia, possibilitou a realização de práticas pedagógicas criativas nascidas da iniciativa do coletivo de professores e alunos que antes eram impedidas de ocorrer por falta de recursos financeiros e de profissionais com dedicação integral.

A quinta escola pesquisada, diante dos questionamentos dos alunos que não integravam as turmas contempladas no ProEMI, respondia que, no próximo ano, os demais alunos (de outras turmas) teriam a oportunidade de participar. No entanto, o Programa foi desativado, fato que causou muita frustração em alunos e professores. "E, nós não chegamos a colher os frutos disso porque acabou [...], quando o caminho foi traçado, de onde a gente via, tinha o interesse do aluno. Quando foi descoberto o caminho, acabou" (Diretor 5, 2016). A descontinuidade do Programa produziu frustração, pois houve uma dedicação intensa de muitos docentes que foi simplesmente desconsiderada. Os professores alegam que, "se tivesse continuado, o ProEMI e o Pnem [Pacto Nacional pelo Fortalecimento do Ensino Médio], a gente poderia estar com uma escola hoje bem diferente talvez, né?" (Coordenadora 5, 2016).

Segundo os dados coletados com a aplicação do questionário, 79\% dos respondentes afirmaram que a participação no ProEMI estimulou a autonomia dos alunos nas atividades escolares e melhorou o seu desempenho. Podemos assegurar que essa visão sobre os aspectos significativos ocorridos na escola com a implantação do Programa é derivada do protagonismo dos trabalhadores que, com acesso a um pouco dos recursos financeiros, deram "asas" a projetos engavetados por falta de apoio. Ou seja, a escola é um campo fértil de práticas significativas de aprendizagem desde que tenha políticas de indução de seu potencial.

O Diretor 5 ressaltou que, embora avanços significativos tenham acontecido em relação ao interesse dos alunos durante o Programa, não podemos afirmar que tenha havido uma significativa alteração dos índices de evasão ou reprovação. O tempo de duração do projeto foi curto para alterar consideravelmente o contexto escolar. No final de 2016, o Governo Michel Temer (2016-2018) pôs fim ao ProEMI, interrompendo algumas experiências inovadoras que estavam apenas no seu início.

\section{Considerações finais}

Com base nos dados analisados, este texto procurou responder ao terceiro questionamento de Muller (2015) a propósito das políticas públicas. O acento desse questionamento está em identificar os efeitos das políticas sobre a sociedade: como medir ou avaliar o impacto de uma política no campo social e econômico? A questão é saber se a política estudada modificou o tecido social que esperava afetar e em que medida seus efeitos estão em conformidade com as expectativas daqueles que a decidiram. 
Especificamente, para nós importa saber se o ProEMI alterou a dinâmica das escolas pesquisadas e se sua implantação esteve de acordo com as normatizações do MEC. É importante destacar que a chegada de uma política educacional no interior das escolas faz parte de um cenário mais amplo e, nesse caso, no campo global, tratou-se de um período de convivência de políticas neoliberais com políticas desenvolvimentistas (2009-2015). Enquanto as primeiras se movimentavam na direção da transferência das ações para o setor privado, as últimas enfatizavam uma postura mais ativa do Estado na promoção do desenvolvimento brasileiro. Com certeza, essa tensão refletia na política educacional, especialmente quando observamos a ausência de políticas integradoras em favor da organização do sistema nacional de educação.

Na correlação de forças no interior da sociedade civil e política, foram criados alguns programas de cariz protetor do direito público à educação, sendo o ProEMI um exemplo. Entretanto, pelo que foi relatado com base nos dados levantados na pesquisa, somente podemos afirmar que o Programa promoveu alterações de curto prazo no tecido da escola e essas alterações não seguiram ipsis litteris as normatizações dele, o que acreditamos que nem poderia ser assim. Importante também sublinhar a interferência das altas taxas de rotatividade dos professores na execução do Programa, já que um corpo docente estável costuma ser mais integrado e ter mais capacidade de evitar descontinuidades no projeto pedagógico da escola (Ingersoll, 2001).

Entendemos o ProEMI como uma política educacional em construção pelos próprios sujeitos da escola com base na sua realidade. Cada unidade de ensino identificou elementos que poderiam, no seu contexto, enriquecer a prática docente, os quais, até então, não estavam disponíveis na organização da rede estadual de ensino.

A gestão dos recursos recebidos via ProEMI proporcionou às escolas, aos seus estudantes e aos docentes experiências até então não vivenciadas por esses sujeitos, com novas relações de trabalho e de perspectivas de ensino-aprendizagem. Isso não é tudo o que o Programa se propôs a realizar, mas é algo novo, simbólico e representativo do investimento estatal no ensino médio, movimento que, na atualidade, caminha do lado oposto.

À Secretaria de Estado da Educação (Sedu) do Espírito Santo cabe a crítica pela insuficiência de suas orientações junto às Superintendências Regionais, pois orientou a elaboração dos PRCs desconectada de uma reflexão sobre a discussão curricular. Ademais, um predicativo fundamental para a execução do ProEMI era adequar as condições de trabalho dos docentes para favorecer a permanência dos professores e alunos em tempo integral na escola. Infelizmente, essa organização somente foi garantida pela Sedu para alguns professores, com efeitos nocivos para a criação de um trabalho integrado e pautado na reflexão de um novo currículo, cuja base estava nos estudos das DCN.

Considerando a perspectiva analítica adotada neste texto de que os trabalhadores docentes podem criar e/ou recriar uma política pública com base nos referenciais global e setorial que perpassam suas histórias, 
mas também nas estruturas cognitivas de seu meio, observamos que essa tradução foi feita a partir de uma tradução anterior executada pelos técnicos da Sedu na leitura dos documentos normativos do MEC. Ou seja, evidenciamos que o trabalho nas escolas foi desenvolvido com base nas orientações normativas da Sedu e, dessa forma, podemos dizer que ocorreu a tradução da tradução do ProEMI.

Nesse sentido, a pequena ênfase na mudança do currículo escolar observada pela coleta dos dados revela não somente a falta de interesse da Sedu nessa discussão, mas também a forma encontrada pelos técnicos da Secretaria de adequar um programa federal à realidade organizacional de suas escolas. Provavelmente, para a Sedu, o recebimento de recursos financeiros do MEC era o mais importante e, por isso, o estado aceitou participar do Programa. Outro elemento importante que reforça essa interpretação é o fato de que o governo do Espírito Santo não era alinhado ao governo federal. Consequentemente, o único interesse do sistema estadual foi se apropriar do recurso financeiro nacional, sem focar os princípios pedagógicos do Programa de reestruturação curricular.

Podemos afirmar que quatro das cinco escolas da amostra, em seus tempos e dinâmicas próprias, promoveram mudanças com o ProEMI, tendo em conta os constrangimentos das estruturas sociais e as margens de liberdade dos seus profissionais. Apenas uma escola permaneceu no seu movimento sequencial de práticas pedagógicas desvinculadas de uma política educacional que pensou e investiu (mesmo com limites) no protagonismo de seus atores.

Os achados de nossa pesquisa se articulam com o conjunto de conhecimentos já produzidos no campo (Silva, 2016; Jakimiu, 2014; Isleb, 2014; Majeski, 2013): o ProEMI possibilitou maior integração entre professores e entre alunos e professores; maior participação e curiosidade por parte dos estudantes; maior interesse dos alunos em aprender e participar das atividades escolares; mudanças tímidas na reestruturação curricular; integração e diversificação do currículo mais afinadas com o público jovem; e indução de práticas de ensino inovadoras; e dificilmente uma política educacional alcança grande êxito quando não altera a lógica organizativa da escola atual e as condições de trabalho do conjunto dos docentes.

Por fim, entendemos que a escola, de muitas maneiras, mostra que está em constante movimento e que os sujeitos que dela fazem parte não se apresentam passivos ao recebimento de determinações centralizadas. Esses indivíduos se manifestam em fala, articulação, negação, construção de projetos, contestação, aprovação, incentivo e identificação com a política do ProEMI. Para isso, esse movimento se desenrolou entre as interferências do referencial setorial e global que perpassam suas histórias escolares. Essas questões precisam ser enfrentadas, em sua totalidade, por uma política educacional de valorização da escola pública, laica, gratuita e com qualidade socialmente referenciada. 


\section{Agradecimentos}

Pesquisa financiada pelo Conselho Nacional de Desenvolvimento Científico e Tecnológico (CNPq), Processo no 482975/2013-0.

\section{Referências}

BORMANN, A. C. O programa ensino médio inovador e a proposta de integração curricular para o ensino médio. Revista Interdisciplinar, Mossoró, v. 3, n. 7, p. 21-31, jan. 2017.

BRASIL. Ministério da Educação (MEC). Portaria nº. 971, de 09 de outubro de 2009. Institui o Programa Ensino Médio Inovador. Brasília, DF, 2009. Disponível em: <http://portal.mec.gov.br/index. php?option $=$ com_docman\&view $=$ download\&alias $=1634$-port971\&Itemid=30192 > . Acesso em: 18 ago. 2021.

BRASIL. Ministério da Educação (MEC). Programa Ensino Médio Inovador: documento orientador. Brasília, DF: MEC/SEB, 2011.

BRASIL. Ministério da Educação (MEC). Avaliação da implantação do programa ensino médio inovador (2009-2013): relatório parcial: novembro de 2011 a novembro de 2012. Brasília: MEC/SEB, 2013.

BRASIL. Ministério da Educação (MEC). Programa Ensino Médio Inovador: documento orientador. Brasília, DF: MEC/SEB, 2014.

BRASIL. Ministério da Educação (MEC). PDE interativo. Brasília, 2015. $<$ pdeinterativo.mec.gov.br/listaEscolasContempladasProemi.php>. Acesso em 13 fev. 2015.

BRASIL. Ministério da Educação (MEC). Conselho Nacional de Educação (CNE). Câmara da Educação Básica (CEB). Parecer nº 5, de 4 de maio de 2011. Diretrizes Curriculares Nacionais para o Ensino Médio. Diário Oficial da União, Brasília, DF, 24 jan. 2012a. Seção 1, p. 10.

BRASIL. Ministério da Educação (MEC). Conselho Nacional de Educação (CNE). Conselho Pleno (CP). Parecer no 11, de 30 de junho de 2009. Proposta de experiência curricular inovadora do Ensino Médio. Diário Oficial da União, Brasília, 25 ago. 2009. Seção 1, p. 11.

BRASIL. Ministério da Educação (MEC). Conselho Nacional de Educação (CNE). Câmara da Educação Básica (CEB). Resolução no 2, de 30 de janeiro 2012. Define Diretrizes Curriculares Nacionais para o Ensino Médio. Diário Oficial da União, Brasília, DF, 31 jan. 2012b. Seção 1, p. 20. 
CUNHA, L. A. Educação, estado e democracia no Brasil. São Paulo: Cortez, 2009.

FERREIRA, E. B. A gênese do ProEMI na perspectiva cognitiva das políticas públicas. Arquivos Analíticos de Políticas Educativas, [S.l.], v. 26. n. 167, dez. 2018.

INGERSOLL, R. M. Teacher turnover, teacher shortages, and the organization of schools. Washington: Center for the Study of Teaching and Policy, 2001. Available in: <https://depts.washington.edu/ctpmail/ PDFs/Turnover-Ing-01-2001.pdf>. Access in: 29 Apr. 2015.

ISLEB, V. O programa ensino médio inovador e sua relação com os dados de fluxo escolar. 2014. 171 f. Dissertação (Mestrado) - Setor de Educação, Universidade Federal do Paraná, Curitiba, 2014.

JAKIMIU, V. Políticas de reestruturação curricular no ensino médio: uma análise do Programa Ensino Médio Inovador. 2014. 188 f. Dissertação (Mestrado) - Setor de Educação, Universidade Federal do Paraná, Curitiba, 2014.

MAJESKI, S. Ensino médio, currículo e cotidiano escolar: sobre movimentos e tensões nos discursos oficiais. 2013. $121 \mathrm{f}$. Dissertação (Mestrado) - Centro de Educação, Universidade Federal do Espírito Santo, Vitória, 2013.

MULLER, P. Les politiques publiques: que sais-je? Paris: Presses universitaires de France-Humensis, 2015.

MULLER, P.; SUREL, Y. As análises das políticas públicas. Pelotas: Educat, 2002.

ESPÍRITO SANTO. Secretaria de Estado da Educação (SEDU). Subgerência de Estatística Escolar (SEE). Dados educacionais. Vitória: Sedu, 2016.

SILVA, M.R. O programa ensino médio inovador como política de Indução a mudanças curriculares: da proposta Enunciada a experiências relatadas. Educação em Revista, Belo Horizonte, v. 32, n. 2, p. 91-110, abr./jun. 2016.

Recebido em 25 de março de 2020. Aprovado em 7 de junho de 2021. 